\title{
Early outcomes of transcatheter aortic valve replacement in patients with severe aortic stenosis: single center experience
}

\author{
Engin Bozkurt', Telat Keleș ${ }^{1}$, Tahir Durmaz ${ }^{1}$, Murat Akçay ${ }^{1}$, Cenk Sari², Hüseyin Ayhan ${ }^{1}$, Nihal Akar Bayram¹, \\ Abdullah Nabi Aslan², Serdal Baștuğ², Emine Bilen² \\ ${ }^{1}$ Cardiology Department, Yıldırım Beyazıt University, Ankara, Turkey \\ ${ }^{2}$ Cardiology Department, Ataturk Training and Research Hospital, Ankara, Turkey
}

Postep Kardiol Inter 2014; 10, 2 (36): 84-90

DOI: $10.5114 /$ pwki.2014.43511

\begin{abstract}
Introduction: Transcatheter aortic valve implantation is a promising alternative to high risk surgical aortic valve replacement. The procedure is mainly indicated in patients with severe symptomatic aortic stenosis who cannot undergo surgery or who are at very high surgical risk.

Aim: Description early results of our single-center experience with balloon expandable aortic valve implantation.

Material and methods: Between July 2011 and August 2012 , we screened in total 75 consecutive patients with severe aortic stenosis and high risk for surgery. Twenty-one of them were found ineligible for transcatheter aortic valve implantation (TAVI) because of various reasons, and finally we treated a total of 54 patients with symptomatic severe aortic stenosis (AS) who could not be treated by open heart surgery (inoperable) because of high-risk criteria. The average age of the patients was $77.4 \pm 7.1 ; 27.8 \%$ were male and $72.2 \%$ were female. The number of patients in NYHA class II was 7 while the number of patients in class III and class IV was 47.

Results: The average mortality score of patients according to the STS scoring system was $8.5 \%$. Pre-implantation mean and maximal aortic valve gradients were measured as $53.2 \pm 14.1 \mathrm{~mm} \mathrm{Hg}$ and $85.5 \pm 18.9 \mathrm{~mm} \mathrm{Hg}$, respectively. Post-implantation mean and maximal aortic valve gradients were $9.0 \pm 3.0$ and $18.2 \pm 5.6$, respectively $(p<0.0001)$. The left ventricular ejection fraction was calculated as $54.7 \pm 14.4 \%$ before the operation and $58.0 \pm 11.1 \%$ after the operation $(p<0.0001)$. The duration of discharge after the operation was 5.29 days, and a statistically significant correlation between the duration of discharge after the operation and STS was found ( $r=0385, p=0.004)$.

Conclusions: We consider that with decreasing cost and increasing treatment experience, TAVI will be used more frequently in broader indications. Our experience with TAVI using the Edwards-Sapien XT (Edwards Lifesciences, Irvine, CA) devices suggests that this is an effective and relatively safe procedure for the treatment of severe aortic stenosis in suitable patients.
\end{abstract}

Key words: transcatheter aortic valve replacement.

\section{Introduction}

Severe symptomatic aortic stenosis has a poor prognosis with conservative treatment [1]. If patients are left untreated, appearance of symptoms results in a high rate of death: approximately $30-50 \%$ in the first 2 years after symptoms appear [2-4]. Because aortic stenosis is an old-age disease, comorbid situations are usually more frequent in these patients. This situation also makes surgery difficult. In fact, in clinical practice 30\% of severe symptomatic patients cannot be operated on due to multiple coexisting conditions [5-8]. Transcatheter aortic valve implantation (TAVI) was applied in 2002 for the first time in humans by Cribier et al., and a very important alternative treatment had emerged [9]. Since this successful implantation, the reliability of the method has been demonstrated by many observational and randomized (PARTNER) studies, and the method has provided a significant improvement for symptomatic aortic stenosis (AS) patients who cannot undergo surgery compared to drug treatment [10]. Despite the wide range of application in Europe and in the United States, the use of TAVI in Turkey was tardily started in 2009 [11]. As far as we know, our clinic has become a center with one of the

\section{Corresponding author:}

Cenk Sari MD, Cardiology Department, Ataturk Training and Research Hospital, Bilkent, 06000 Ankara, Turkey, phone: +903122912525, e-mail: cengaver61@yahoo.com

Received: 27.12.2013, accepted: 15.01.2014. 
most extensive series in Turkey with respect to balloon expandable aortic valve implantation.

\section{Aim}

In the present article, we aim to share the results from our clinic as a single-center experience.

\section{Material and methods}

Between July 2011 and August 2012, we screened in total 75 patients who had severe aortic stenosis and high risk for surgery. Twenty-one of them were found ineligible for TAVI because of the reasons listed as follows: two of them had a very critical health status (severe left ventricular dysfunction and cardiogenic shock) and we performed balloon aortic valvuloplasty (BAV) as a bridge surgery but patients were lost because of cardiogenic shock. Six of them refused both surgery and TAVI. Four of them were found unsuitable for TAVI and surgery because of incurable malignancy (2) (life expectancy $<1$ year), and severe neurological deficits in which cases the TAVI procedure was not expected to improve the patient's functional status or quality of life [2]. Nine of them were found suitable for surgery with the decision of the "heart team" consisting of cardiologist, heart surgeon, anesthesiologist and radiologist (low risk or two valve disease). Finally, we performed TAVI with an Edwards Sapien XT valve (Edwards Lifesciences, Irvine, CA) in a total of 54 patients who were admitted to our clinic with symptomatic severe AS who could not undergo surgery because of high-risk criteria.

\section{Inclusion criteria}

Patients had to primarily fulfill the criteria of severe symptoms (according to New York Heart Society class II, III and IV) and echocardiographically important AS (aortic valve area $<0.8 \mathrm{~cm}^{2}$, mean systolic aortic valve pressure gradient $>40 \mathrm{~mm} \mathrm{Hg}$ or aortic velocity $4.0 \mathrm{~m} / \mathrm{s}$ ). In addition, the peripheral vascular bed had to be wide enough for the process (> $6.0 \mathrm{~mm}$ ) and the aortic annulus diameter $18-28 \mathrm{~mm}$. Patients fitting the above criteria went through evaluation by the heart team. After evaluation of those who were appropriate as being inoperable for aortic valve replacement, or who had a very high risk for an operation, a plan was made for a TAVI procedure. Of those patients, those with comorbidities such as malignancy or liver cirrhosis were evaluated by the experts of the corresponding branch. The patients with an expected life-span longer than 1 year were considered to be suitable for the TAVI procedure. The risk assessment of patients was calculated according to the Society of Thoracic Surgeons (STS) scoring system [12].

\section{Transcatheter aortic valve implantation procedure exclusion criteria}

Patients with bicuspid aortic valve, non-calcified aortic stenosis, unsuitable annulus diameter, a history of stroke within the last 6 months, a life expectancy less than 1 year due to comorbidities, or an additional comorbidity that prevented any symptomatic relief as a result of TAVI were excluded from the study.

\section{Imaging procedures}

First, all patients were evaluated by transthoracic echocardiography (TTE), and then patients lacking contraindications for TAVI were evaluated by transesophageal echocardiography (TEE). In these evaluations, left ventricular function, aortic valve structure, degree of calcification and stenosis, and aortic valve area, annulus and ascending aorta measurements were recorded. Annulus measurements were performed with both TTE and TEE. During annulus measurements, the points of valve linked to aorta (hinge point to hinge point) were confirmed through zooming and then measurements were obtained. The annulus measurements in patients contraindicated with TEE were performed by TTE and computed tomography $(\mathrm{CT})$. All of the patients before the operation underwent a 3D reconstruction process through contrast-enhanced CT imaging. Both annulus diameters and the distance of coronary arteries to annulus calculated by $\mathrm{CT}$ and also the diameters of arteries to be implemented (femoral artery, subclavian artery, abdominal aorta), calcification degree, tortuosity, and the division level of superficial and profunda femoral artery branches were detected. The patients with insufficient femoral artery diameter $(<6 \mathrm{~mm})$, having severe tortuosity, calcification or significant narrowing of the arteries above the femoral artery level were treated through a subclavian route. Coronary angiography procedures were performed for all patients before the TAVI operation. After coronary angiography, patients requiring revascularization were given revascularization before TAVI. In addition, in order to determine the peripheral insertion site, angiography was performed using the digital subtraction technique in a manner to visualize the iliac and femoral arteries.

\section{Transcatheter aortic valve implantation procedure}

All TAVI procedures were performed in the catheter laboratory under local anesthesia along with deep sedation or general anesthesia. Despite the use of TEE with most of the patients, TEE was not applied for 1 patient with esophageal varices and 1 patient with esophageal stricture depending on exposure to corrosive substances. The artery in which the valve was to be moved was opened by surgical cut down in 8 patients. Five of them were the femoral artery and 3 of them were subclavian arteries. In the remaining 46 patients, TAVI was performed using the Prostar ${ }^{\circledR}$ XL (ProStar $^{\mathrm{TM}}$ XL10Fr, Abbott Vascular, Abbott Park, IL, USA) closure system through an entirely percutaneous technique. Details of the device and technical aspects of the procedure have been previously published [13]. 
During Edwards Sapien XT valve implantation, attention was paid to the prosthetic valve to position it in the middle ( $50 \%-50 \%)$, according to the annulus line using both TEE and angiographic imaging. Aortic root angiography was performed after the procedure to evaluate aortic insufficiency, valve position, flow in coronary arteries, and Valve Academic Research Consortium (VARC) specifications [14]. The peripheral entry site was then closed and angiographic control was performed. Peripheral blood vessels were evaluated especially for complications such as dissection, rupture and blockage. In case of detection of any complication, it was treated by peripheral stenting or a surgical method. During procedure, a bolus of intravenous heparin $(60 \mathrm{lU} / \mathrm{kg})$ was administered to achieve a target activated clotting time (ACT) of $250 \mathrm{~s}$ to $300 \mathrm{~s}$, and the ACT was measured every 30 min thereafter. If the

Table I. General characteristics

\begin{tabular}{|c|c|}
\hline Patient characteristics & Results \\
\hline Male/female, $n$ & $15 / 39$ \\
\hline Age, mean \pm SD [years] & $77.4 \pm 7.1(46-97)$ \\
\hline BMI, mean (range) $\left[\mathrm{kg} / \mathrm{m}^{2}\right]$ & $26.7(17-36.9)$ \\
\hline Functional capacity (NYHA class II), $n$ & 7 \\
\hline NYHA class III or IV, $n$ & 47 \\
\hline STS score & $8.5(1.2-31.2)$ \\
\hline $\begin{array}{l}\text { SURTAVI risk model } \\
\text { (low/intermediate/high), } n\end{array}$ & $5 / 14 / 35$ \\
\hline Comorbid conditions & Results \\
\hline Coronary artery disease, $n$ & 36 \\
\hline Hypertension, $n$ & 43 \\
\hline Diabetes mellitus, $n$ & 16 \\
\hline COPD (moderate to severe), $n$ & 32 \\
\hline $\begin{array}{l}\text { Impaired renal function } \\
\text { (creatinine }>1.3 \mathrm{mg} / \mathrm{dl}), n\end{array}$ & 13 \\
\hline Liver function disorder, $n$ & 1 \\
\hline $\begin{array}{l}\text { Peripheral arterial disease } \\
\text { (carotid, renal, distal extremity) }\end{array}$ & 26 \\
\hline Atrial fibrillation, $n$ & 13 \\
\hline Pre-operation revascularization, $n$ & 10 \\
\hline Annulus-LMCA distance $[\mathrm{cm}]$ & 12.7 \\
\hline
\end{tabular}

Table II. Baseline echocardiographic variables

\begin{tabular}{lc} 
Echocardiographic variables & Results \\
\hline Aortic annulus diameter, mean (range) $[\mathrm{cm}]$ & $20.8(18-24)$ \\
\hline AVA, mean (range) $\left[\mathrm{cm}^{2}\right]$ & $0.65(0.4-0.8)$ \\
\hline Severe left ventricular dysfunction $(\mathrm{EF}<35 \%), n$ & 8 \\
\hline Mild aortic regurgitation, $n$ & 23 \\
\hline Moderate aortic regurgitation, $n$ & 14 \\
\hline Severe aortic regurgitation, $n$ & 1 \\
\hline $\begin{array}{l}\text { Peak systolic pulmonary artery pressure, mean } \\
\text { (range) [mm Hg] }\end{array}$ & $45.5(30-70)$
\end{tabular}

target ACT isn't achieved, an additional bolus dose according to ACT level were added.

\section{Follow-up after transcatheter aortic valve implantation procedure}

We followed our patients clinically and echocardiographically immediately after the procedure in the operating room by TEE and at predischarge, 1 month, 3 months, 6 months after discharge by TTE. Dual (aspirin and clopidogrel) antiplatelet therapy was given to all patients for up to 6 months. In situations where use of oral anticoagulant therapy was essential after the procedure, such as in atrial fibrillation, warfarin therapy was started for 1 month to an INR value around 2-2.5 and combined with dual antiplatelet therapy. One month later, aspirin and warfarin therapy were continued while stopping use of clopidogrel. Cardiovascular events and clinical endpoints were recorded according to the VARC classification.

\section{Statistical analysis}

Statistics in the present study were performed using the SPSS package (SPSS Inc., Chicago, Illinois, USA) version 17.0. Data containing continuous quantitative variables and categorical variables are shown in the form of mean \pm standard deviation and percentage (\%), respectively. The $t$-test was used to compare the means of pre- and post-operation parametric variables, while non-parametric parameters were evaluated by Wilcoxon test. Value of $p<0.05$ was considered to be statistically significant.

\section{Results}

The present study contains the in-hospital and shortterm (30-day and 180-day) results of 54 TAVI cases (39 women, 15 men, average age $77.4 \pm 7.1$ years) who were treated in our hospital between July 2011 and August 2012. All of the patients had been considered either too risky for open-heart surgery or inoperable because of severe calcific aortic stenosis due to additional cardiovascular or other systemic diseases. General characteristics of the patients are summarized in Table I. The average age of patients was $77.4 \pm 7.1$ years with $27.8 \%$ male and $72.2 \%$ female. The number of patients in NYHA class II was 7 while the number of patients in class III and class IV was 47. The average mortality score of patients according to the STS scoring system was $8.5 \%$. According to the SURTAVI risk model, 5 patients had low risk, 14 patients had intermediate risk and 35 had high risk.

As comorbidity factors, $79.6 \%$ of our patients had hypertension, $29.6 \%$ had diabetes mellitus, $62 \%$ had moderate-to-severe chronic obstructive pulmonary disease, and $53.1 \%$ had peripheral artery disease (carotid, renal, and distal peripheral artery disease). $66.7 \%$ of the patients had coronary artery disease and $27.7 \%$ had coronary revasculariza- 
Table III. Echocardiographic variables before and after TAVI

\begin{tabular}{lccc} 
Echocardiographic variables & Before TAVI & After TAVI & Value of $p$ \\
\hline Maximal gradient, mean \pm SD $[\mathrm{mm} \mathrm{Hg}]$ & $85.5 \pm 18.9$ & $18.2 \pm 5.6$ & $<0.0001$ \\
\hline Average gradient, mean $\pm \mathrm{SD}[\mathrm{mm} \mathrm{Hg}]$ & $53.2 \pm 14.1$ & $9.0 \pm 3.0$ & $<0.0001$ \\
\hline EF, mean $\pm \mathrm{SD}(\%)$ & $54.7 \pm 14.4$ & $58.0 \pm 11.1$ & $<0.0001$ \\
\hline Mitral regurgitation moderate/high, $n$ & 15 & 1 &
\end{tabular}

tion before the procedure. There were patients among our cases having mitral valve replacement (1), cirrhosis (1), hematologic malignancy (2), and left atrial thrombi (5), which were exclusion criteria of the Partner cohort A/B study.

Pre-implantation mean and maximal aortic valve gradients were measured as $53.2 \pm 14.1 \mathrm{~mm} \mathrm{Hg}$ and 85.5 $\pm 18.9 \mathrm{~mm} \mathrm{Hg}$, respectively. Post-implantation mean and maximal aortic valve gradients were $9.0 \pm 3.0$ and 18.2 \pm 5.6 , respectively $(p<0.0001)$. The left ventricular ejection fraction was calculated as $54.7 \pm 14.4 \%$ before the operation and $58.0 \pm 11.1 \%$ after the operation $(p<0.0001)$. After the procedure, moderate (2) degrees of paravalvular aortic regurgitation were observed in 2 patients and mild degrees of paravalvular aortic regurgitation were found in 21 patients. Before the intervention, $2^{\text {nd }}-3^{\text {rd }}$ degree mitral regurgitation was seen in 15 patients while it was observed in only 1 patient after TAVI (Tables II, III).

Our technical success rate (defined as stable device placement and adequate function in the first attempt as assessed by angiography + echocardiography) was 98.0\%. Our acute procedural success rate (defined as device success with the absence of periprocedural major cardiovascular events including death, tamponade, coronary artery occlusion in the first $24 \mathrm{~h}$ after device implantation) was $92.5 \%$ (50 of 54).

Whereas the average procedure time was $75.5 \mathrm{~min}$, it was noted to decrease to $68.5 \mathrm{~min}$ in the last 10 patients. The amount of contrast dye used during the process was $211 \mathrm{ml}$. The duration of discharge after the operation was 5.29 days and a statistically significant correlation was found between the duration of discharge after the operation and STS ( $r=0385, p=0.004)$ (Table IV).

No clinical stroke was observed in our series. Pericardial effusion requiring surgical intervention was observed in 2 patients. None of the patients required permanent pacemaker implantation. In 1 patient, transient atrioventricular block occurred. He was monitored carefully and after $6 \mathrm{~h}$ the block disappeared and there was no need for permanent pacemaker implantation. Left bundle branch block developed in 1 patient after the procedure. The Prostar closure system was preferred in 46 patients and a surgical method was preferred in 8 patients for the access. Four of the patients that used Prostar required surgical repair due to peripheral dissection and 1 patient was treated with peripheral stenting. Bleeding, vascular access site and prosthetic valve 'associated' complications are listed in Table V.
Table IV. Procedural characteristics

\begin{tabular}{lc} 
Procedural characteristics & Results \\
\hline Valve diameter (23 mm/26 mm) & $35 / 19$ \\
\hline Prostar closure/surgery, $n$ & $46 / 8$ \\
\hline Operation time, mean (range) [min] & $75.5(44-164)$ \\
\hline Contrast volume, mean (range) [ml] & $211(100-350)$ \\
\hline $\begin{array}{l}\text { Post-operation discharge time, mean (range) } \\
\text { [days] }\end{array}$ & $5.29(3-20)$
\end{tabular}

Table V. Bleeding, vascular access site and prosthetic valve 'associated' complications

\begin{tabular}{lcc} 
Complications & Patient & Percent \\
\hline Myocardial infarction $(<72 \mathrm{~h})$ & 0 & 0 \\
\hline Stroke & 0 & 0 \\
\hline Vascular complications: & & \\
\hline \multicolumn{1}{l}{ Major } & 2 & 3.7 \\
\hline Minor & 3 & 5.5 \\
\hline Bleeding: & & \\
\hline \multicolumn{1}{l}{ Life-threatening } & 3 & 5.55 \\
\hline Major & 5 & 9.2 \\
\hline Minor & 4 & 7.4 \\
\hline Pericardial effusion (requiring operation) & 2 & 3.7 \\
\hline $\begin{array}{l}\text { Paravalvular aortic regurgitation } \\
\text { (none/trace/mild/moderate/high) }\end{array}$ & $16 / 15 /$ & $29.6 / 27.7 /$ \\
\hline Temporary during the procedure/ & $21 / 2 / 0$ & $38.8 / 3.7 / 0$ \\
\hline complete AV block & $1 / 0$ & $1.85 / 0$ \\
\hline Permanent pace maker implantation & 0 & 0 \\
\hline Acute renal failure (stage 1/2/3) & $3 / 0 / 0$ & 5.55 \\
\hline Repeat TAVI (valve in valve) & 1 & 1.85 \\
\hline Endocarditis & 0 & 0 \\
\hline Valve embolization & 0 & 0 \\
\hline Coronary obstruction & 0 & 0 \\
\hline
\end{tabular}

\section{Clinical follow-up}

Our patients' survival rate was $94.4 \%$ at the 180 -day follow-up. One patient died as a result of right ventricular rupture due to the pacemaker lead $10 \mathrm{~h}$ after TAVI and 1 patient died in the cath lab as a result of left ventricular rupture immediately after valve implantation. After the discharge, no additional deaths were seen in the first month. In the 1 to 6 months period, 1 patient died due to internal bleeding (while using warfarin + ASA depending 
Table VI. TAVI results (composite end points defined by VARC)

\begin{tabular}{|c|c|c|}
\hline Variables & Patient & Percent \\
\hline In-hospital death, $n$ & 2 & 3.7 \\
\hline \multicolumn{3}{|l|}{ 30-day mortality, $n$ : } \\
\hline All-cause mortality & 2 & 3.7 \\
\hline Cardiovascular-cause mortality & 2 & 3.7 \\
\hline 180-day mortality, $n$ & 3 & 5.55 \\
\hline Successful placement of the device & 53 & 98 \\
\hline Combined security end point (30 days) & 7 & 12.9 \\
\hline Combined security end point (180 days) & 3 & 5.55 \\
\hline $\begin{array}{l}\text { Paravalvular aortic regurgitation (none/ } \\
\text { trace/mild/moderate/high at } 3 \text { months) }\end{array}$ & $\begin{array}{l}11 / 18 / \\
23 / 2 / 0\end{array}$ & $\begin{array}{l}20.4 / 33.4 / \\
42.5 / 3.7 / 0\end{array}$ \\
\hline $\begin{array}{l}\text { Paravalvular aortic regurgitation (none/ } \\
\text { trace/mild/moderate/high at } 6 \text { months) }\end{array}$ & $\begin{array}{l}11 / 18 / \\
23 / 2 / 0\end{array}$ & $\begin{array}{l}20.4 / 33.4 / \\
42.5 / 3.7 / 0\end{array}$ \\
\hline
\end{tabular}

on atrial fibrillation). The 30-day mortality rate was $3.7 \%$ while the 180 -day mortality rate was $5.55 \%$. Although before receiving TAVI $87 \%$ of patients were in NYHA class III or IV, $78 \%$ of the surviving patients were in NYHA functional class I or II at 180-day follow-up. Composite end points according to VARC definitions are given in Table VI.

\section{Echocardiographic follow-up}

At the echocardiographic examinations which were done at 1, 3 and 6 months after TAVI no deterioration was observed in patients with moderate aortic regurgitation. Changes in the degree of aortic regurgitation at 3- and 6-month follow up are given in Table VI. There was minimal worsening in the degree of aortic regurgitation in patients who had previously no or a trace degree of $A R$ after the TAVI procedure (5 patients none to trace degree, 2 patient trace to mild degree).

\section{Discussion}

This study included in-hospital, 30-day and average 180-day clinical follow-up results of a total of 54 TAVI procedures performed in our clinic using transfemoral and subclavian artery methods. Our study contains the results of one of the largest series conducted with balloon expandable valve implantation in a single center in Turkey.

The average age of our patients is similar to those included in the Europe SOURCA [15], German [16], and French [17] studies in addition to the PARTNER study [10]. However, the number of female patients in our series was greater than the number of male patients, which is different than the mentioned studies. The reason for this may be the particular distribution of the elderly population in our country, according to gender. The elderly female population in our country is higher than male (according to
Turkish Statistical Institute data, the male/female ratio over the age of 80 is approximately 1.8) [18].

Our technical success rate for the TAVI procedure was $98 \%$. Only in 1 patient did the valve move up slightly during valve emplacement. By placing a second valve, the procedure was successfully completed in this patient. Post-operation average gradient also yielded similar results to the other studies. Most of the TAVI procedures in our series were performed via the transfemoral method (51) and used a Prostar closure device (46). Three patients had Edwards Sapien XT valve implantation by a surgical technique through the subclavian artery.

There are many reports about TAVI-associated complications. Stroke, pericardial tamponade, severe paravalvular aortic regurgitation, aortic dissection, aortic or cardiac rupture, and the complications in peripheral implantation site are the most serious ones. The other more commonly seen serious complications in patients especially having Corevalve self-expandable valve replacement have the need of permanent pacemaker implantation after intermittent or permanent third-degree block. In our series, only 1 patient developed 6-hour lasting transient AV complete block and a permanent pacemaker requirement did not occur. One patient developed a left branch block after the procedure, but no problem was seen in the follow-ups and the patient was discharged without any intervention. Both patients were monitored by a Holter device at the $1^{\text {st }}$ month control, and no transient AV block was seen. The lowest need for a permanent pacemaker reported with the Edwards valve is in the studies of Sinhal et al. (5.7\%) [19] and the Europe SOURCE [15] registry (7\%). The reasons why none of the patients needed a permanent pacemaker implantation are most likely due to the small number of patients in our series, but also patient selection and not proceeding much toward the left ventricular outflow tract. Especially during valve implantation, the prosthesis valves are implanted by evaluating the valve position very carefully by TEE and/or angiographically and by considering the point where native aortic valves attach to the aorta (considering a $50 \%-50 \%$ or at worst $60 \%-40 \%$ rate).

Pericardial effusion is a commonly seen complication that may cause fatal consequences by proceeding in tamponade. Data from the literature reveal an incidence of pericardial tamponade of 2-8\% [20-23]. Especially the temporary pacemaker lead placed into the right ventricle may damage the thin wall of the right ventricle while beating too fast or may cause pericardial tamponade by tearing the wall [13]. In this case, the pericardial fluid must be immediately drained and in very rare cases the ventricular wall must be repaired if necessary. In our series, only 2 in-hospital deaths were reported and the reason for the first case was right ventricle rupture while the reason for the other was left ventricle rupture. Because this is a very serious and fatal complication, patients 
must be monitored by serial echocardiographic evaluation after the operation and the cardiac surgeons must be aware of the situation as soon as possible, keeping the operating room ready in case of emergency.

One of the most commonly seen complications in TAVI is vascular complications and our series showed similar results as the others. The major peripheral complication rate was $16 \%$ in the PARTNER study [10], $6.3 \%$ in the French registry study containing Edwards valve replacement, and 3.7\% in our series [17]. Despite the increased mortality rate in patients with vascular complications [17], no mortality was observed in our patients who had vascular complications [24-26].

Although in one study it was reported that vascular complications had fatal results and this was mostly related to the Prostar closure device, no fatal bleeding complications related to the Prostar closure device were seen in our study [27]. A need for surgical repair emerged in 2 patients due to the vascular complication related to the Prostar closure device. Before the use of the Prostar device, evaluation of the diameter, degree of calcification and tortuosity conditions of the peripheral arteries used for access are highly important to reduce peripheral complications. If the femoral artery is planned to be used as an access in the TAVI procedure, the division points of superficial and profunda branches should be clearly determined by both CT angiography and peripheral digital subtraction angiography and the intervention should be performed above this division point.

Stroke is one of the important and catastrophic complications of TAVI and its rate was $4.6 \%$ in the PARTNER [10] study. Stroke was most commonly observed during implantation and position setting of the valve. In our series none of the patients had stroke. This is because we followed up our patients clinically with neurological examination and we did not use brain magnetic resonance imaging (MRI) routinely.

Paravalvular aortic regurgitation was the most common complication of TAVI. In our series, 15 (27.7\%) patients had a trace degree, 21 (38.8\%) patients had a mild degree and 2 (3.7\%) patients showed a moderate degree of paravalvular AR. No severe AR was observed in any patient immediately after the procedure or during 6-month follow-up. At the 6-month follow-up of patients with moderate aortic regurgitation, no increase was detected in the degree of AR. The rate of moderate-to-severe paravalvular AR in the literature is reported as 7-30\% [10, 15, 16]. In our series, lack of severe AR might be explained by proper selection of the appropriate aortic valve size for the annulus. In our clinic, we decided on the optimal valve size by performing TTE, TEE, 3-dimensional TEE and CT measurements before the procedure. In some studies that compared 3-dimensional TEE measurements to 2-dimensional measurements, 3D TEE led to a change in the decision of the size of the prosthetic valve in ap- proximately $26 \%$ of patients. This finding emphasizes the importance of 3-dimensional TEE in measurement and verification of the best-suited valve size [10, 15, 28, 29]. Annulus measurements with 3-dimensional multislice computed tomography offers the possibility of measuring the value that is closest to reality. Similar to 3-dimensional echo, measurements made with multislice computed tomography have been shown to change the TAVI strategy by $40 \%$ [30]. However, lack of specialized radiologists in this field is the biggest handicap and it forces us as cardiologists to consult three-dimensional TEE measurements more often. For this reason, a multidisciplinary team approach, including a permanent radiologist in the TAVI team to evaluate peripheral arteries and to try to obtain the most appropriate measures in annulus measurements with team-work, would be reasonable.

At baseline echocardiographic evaluation, 15 patients had $2^{\text {nd }}-3^{\text {rd }}$ degree mitral regurgitation while it was observed in only 1 patient after the TAVI. Similarly, in a study conducted by Webb et al. [31] in 48\% of patients with moderate to severe MR, MR regressed after TAVI. The pathophysiological mechanism behind this improvement can be explained as follows: as a result of longstanding severe AS, chronic pressure load results in concentric hypertrophy of the left ventricle and a high transmitral pressure gradient. As a result, MR can progress or functional MR can develop. Because of concomitant volume load, and development of diastolic dysfunction, mitral annular dilatation leads to progression of functional MR [32]. Most of our patients with MR had normal or nearly normal mitral valve structure called functional mitral regurgitation and therefore MR improved significantly after TAVI.

Our in-hospital mortality rate (3.7\%) and 30-day mortality rate $(3.7 \%)$ were lower than those in the German registry study (8.2\%/12.4\%) and the average 180-day mortality rate $(5.5 \%)$ was lower than those in many larger studies [10, 15-17]. These findings might be due to the relatively low risk score in our patients and being rigorous both in patient selection and in the evaluation of patients before the TAVI operation. The small number of patients is the major limitation of our study and this may have caused a lower adverse event rate compared with larger studies.

\section{Conclusions}

The TAVI method has been rapidly improving as a crucial and vital alternative for patients who are inoperable or who have a high risk for surgery due to comorbid conditions. Patient selection for TAVI is of considerable importance in optimizing procedural and long-term outcomes. It is important for cardiologists in our country to refer patients with severe aortic stenosis after diagnosis to the centers performing TAVI in order to assess the possibility of TAVI use. Thereby, at a time when tens of thousands of patients with aortic stenosis have been treated in Europe and America, it would be more widespread for people in our country as well. 


\section{References}

1. Aronow WS, Ahn C, Kronzon I, Nanna M. Prognosis of congestive heart failure in patients aged $>$ or $=62 \mathrm{y}$ with unoperated severe valvular aortic stenosis. Am J Cardiol 1993; 72: 846-8.

2. Turina J, Hess O, Sepulcri F, Krayenbuehl HP. Spontaneous course of aortic valve disease. Eur Heart J 1987; 8: 471-83.

3. Kelly TA, Rothbart RM, Cooper CM, et al. Comparison of outcome of asymptomatic to symptomatic patients older than 20 years of age with valvular aortic stenosis. Am J Cardiol 1988; 61: 123-30.

4. Bonow RO, Carabello BA, Chatterjee K, et al. 2008 Focused update incorporated into the ACC/AHA 2006 guidelines for the management of patients with valvular heart disease: a report of the American College of Cardiology/American Heart Association Task Force on Practice Guidelines (Writing Committee to Revise the 1988 Guidelines for the Management of Patients With Valvular Heart Disease): endorsed by the Society of Cardiovascular Anesthesiologists, Society for Cardiovascular Angiography and Interventions, and Society of Thoracic Surgeons. Circulation 2008; 118: e523-661.

5. Bouma BJ, van den Brink RBA, van der Meulen JHP, et al. To operate or not on elderly patients with aortic stenosis: the decision and its consequences. Heart 1999; 82: 143-8.

6. lung B, Cachier A, Baron G, et al. Decision-making in elderly patients with severe aortic stenosis: why are so many denied surgery? Eur Heart J 2005; 26: 2714-20.

7. Varadarajan P, Kapoor N, Bansal RC, Pai RG. Clinical profile and natural history of 453 nonsurgically managed patients with severe aortic stenosis. Ann Thorac Surg 2006; 82: 2111-5.

8. Bach DS, Siao D, Girard SE, et al. Evaluation of patients with severe symptomatic aortic stenosis who do not undergo aortic valve replacement. Circ Cardiovasc Qual Outcomes 2009; 2: 533-9.

9. Cribier A, Eltchaninoff $\mathrm{H}$, Bash A, et al. Percutaneous transcatheter implantation of an aortic valve prosthesis for calcific aortic stenosis: first human case description. Circulation 2002; 106: 3006-8.

10. Leon MB, Smith CR, Mack M, et al.; PARTNER Trial Investigators. Transcatheter aortic-valve implantation for aortic stenosis in patients who cannot undergo surgery. N Engl J Med 2010; 363: 1597-607.

11. Yücel G, Paker T, Akçevin A, et al. Transcatheter aortic valve implantation: the first applications and early results in Turkey. Arch Turk Soc Cardiol 2010; 38: 258-63.

12. Shroyer AL, Coombs LP, Peterson ED, et al. The Society of Thoracic Surgeons: 30-day operative mortality and morbidity risk models. Ann Thorac Surg 2003; 75: 1856-64.

13. Webb JG, Pasupati S, Humphries K, et al. Percutaneous transarterial aortic valve replacement in selected high-risk patients with aortic stenosis. Circulation 2007; 116: 755-63.

14. Leon MB, Piazza N, Nikolsky E, et al. Standardized endpoint definitions for transcatheter aortic valve implantation clinical trials: a consensus report from the Valve Academic Research Consortium. J Am Coll Cardiol 2011; 57: 253-69.

15. Thomas M, Schymik G, Walther T, et al. One-year outcomes of cohort 1 in the Edwards SAPIEN Aortic Bioprosthesis European Outcome (SOURCE) registry: the European registry of transcatheter aortic valve implantation using the Edwards SAPIEN valve. Circulation 2011; 124: 425-33.

16. Zahn R, Gerckens U, Grube E, et al.; Transcatheter aortic valve implantation: first results from a multi-centre real-world registry. German Transcatheter Aortic Valve Interventions-Registry Investigators. Eur Heart J 2011; 32: 198-204.
17. Eltchaninoff H, Prat A, Gilard M, et al.; FRANCE Registry Investigators. Transcatheter aortic valve implantation: early results of the FRANCE (French Aortic National CoreValve and Edwards) registry. Eur Heart J 2011; 32: 191-207.

18. Turkish Statistical Institute. Women in Statistics 2011. Ankara Turkish Statistical Institute, Printing Division, Ankara March 2013.

19. Sinhal A, Altwegg L, Pasupati S, et al. Atrioventricular block after transcatheter balloon expandable aortic valve implantation. JACC Cardiovasc Interv 2008; 1: 305-9.

20. Zierer A, Wimmer-Greinecker G, Martens S, et al. The transapical approach for aortic valve implantation. J Thorac Cardiovasc Surg 2008; 136: 948-53.

21. Descoutures F, Himbert D, Lepage L, et al. Contemporary surgical or percutaneous management of severe aortic stenosis in the elderly. Eur Heart J 2008; 29: 1410-7.

22. Grube E, Buellesfeld L, Mueller R, et al. Progress and current status of percutaneous aortic valve replacement: results of three device generations of the CoreValve Revalving system. Circ Cardiovasc Intervent 2008; 1: 167-75.

23. Cribier A, Eltchaninoff H, Tron C, et al. Treatment of calcific aortic stenosis with the percutaneous heart valve: mid-term follow-up from the initial feasibility studies: the French experience. J Am Coll Cardiol 2006; 47: 1214-23.

24. Van Mieghem NM, Nuis RJ, Piazza N, et al. Vascular complications with transcatheter aortic valve implantation using the $18 \mathrm{Fr}$ Medtronic Core- Valve System: the Rotterdam experience. Eurointervention 2010; 5: 673-9.

25. Tchetche D, Dumonteil N, Sauguet A, et al. Thirty-day outcome and vascular complications after transarterial aortic valve implantation using both Edwards Sapien and Medtronic CoreValve bioprostheses in a mixed population. Eurointervention 2010; 5 : 659-65.

26. Kahlert P, Al-Rashid F, Weber M, et al. Vascular access site complications after percutaneous transfemoral aortic valve implantation. Herz 2009; 34: 398-408.

27. Dager AE, Nuis RJ, Caicedo B, et al. Colombian experience with transcatheter aortic valve implantation of Medtronic CoreValve. Tex Heart Inst J 2012; 39: 351-8.

28. Gilard M, Eltchaninoff $\mathrm{H}$, lung B, et al.; FRANCE 2 Investigators. Registry of transcatheter aortic-valve implantation in high-risk patients. N Engl J Med 2012; 366: 1705-15.

29. Husser O, Rauch S, Endemann DH, et al. Impact of three-dimensional transesophageal echocardiography on prosthesis sizing for transcatheter aortic valve implantation. Catheter Cardiovasc Interv 2012; 80: 956-63.

30. Messika-Zeitoun D, Serfaty JM, Brochet E, et al. Multimodal assessment of the aortic annulus diameter: implications for transcatheter aortic valve implantation. J Am Coll Cardiol 2010; 55: 186-94.

31. Webb JG, Pasupati S, Humphries K, et al. Percutaneous transarterial aortic valve replacement in selected high-risk patients with aortic stenosis. Circulation 2007; 116: 755-63.

32. Sarl C, Aslan AN, Keleș T, Bozkurt E. Significant reduction in mitral regurgitation after transcatheter aortic valve implantation in a patient with severe degenerative aortic valve disease, moderate to severe mitral regurgitation, and normal ejection fraction. Turk Kardiyol Dern Ars 2012; 40: 527-31. 